\title{
Viabilidade econômica do uso de fontes lipídicas na dieta de vacas em lactação
}

\author{
[Economic viability of using lipidic sources in the diet of lactating cows] \\ R.M. Murta ${ }^{1}$, C.M. Veloso ${ }^{2}$, F.F. Silva ${ }^{3}$, A.J.V. Pires ${ }^{3}$, A.L. Rocha Neto ${ }^{3}$, \\ L.T. Costa ${ }^{3}$, H.A.D. Santana Júnior ${ }^{3}$ \\ ${ }^{1}$ Instituto Federal do Norte de Minas Gerais - IFNMG - Campus Salinas - Salinas, MG \\ ${ }^{2}$ Universidade Federal de Viçosa - UFV - Viçosa, MG \\ ${ }^{3}$ Universidade Estadual do Sudoeste da Bahia - Itapetinga, BA
}

\begin{abstract}
RESUMO
Objetivou-se, com este estudo, avaliar a viabilidade econômica do uso de diferentes fontes lipídicas na dieta. O trabalho foi implantado em uma área de 42ha, dividida em oito piquetes, formada de Brachiaria brizantha. Utilizaram-se 12 vacas mestiças Holandês x Zebu, distribuídas em três quadrados latinos $4 \mathrm{x}$ 4. Os quatro tratamentos foram constituídos de diferentes fontes lipídicas, como se segue: dieta sem fonte extra de lipídeos; dieta com caroço de algodão; dieta com óleo de soja; e dieta com óleo de soja de fritura. As dietas foram calculadas para suprir as exigências de mantença e produção de $15 \mathrm{~kg}$ de leite/dia, com 3,5\% de gordura. Utilizaram-se, para efeito de estudo da análise econômica, dois indicadores econômicos, valor presente líquido e taxa interna de retorno. O custo total por animal e por litro de leite produzido aumentou com a utilização das fontes lipídicas na dieta. Todos os tratamentos apresentaram valores positivos para lucro por animal, sendo observados valores de $\mathrm{R} \$ 2,82 ; \mathrm{R} \$ 2,68 ; \mathrm{R} \$ 2,39$ e $\mathrm{R} \$$ 2,09 para os tratamentos ausente de fonte extra de lipídeos; óleo de soja de fritura; caroço de algodão e óleo de soja, respectivamente. A taxa interna de retorno foi mais vantajosa quando não se utilizou fonte lipídica na dieta, o que demonstra que este tratamento é economicamente mais interessante para um investidor, gerando $0,73 \%$ ao mês. O cálculo do valor presente líquido demonstra que este investimento é viável para todos os tratamentos com taxa de $6 \%$ de desconto. O tratamento sem fonte extra de lipídeos apresentou menor custo de produção e, consequentemente, melhor relação custo-benefício. Para taxas de retorno do valor presente líquido de 10 e $12 \%$, a produção leiteira torna-se inviável para todos os tratamentos.
\end{abstract}

Palavras-chave: custo de produção, desempenho, gordura, retorno econômico

\begin{abstract}
The objective was to evaluate the economic viability of using different lipid sources in the diet of lactating cows. The experiment was done in an area of 42ha, divided into eight paddocks with an average size of approximately 5.3ha each, consisting of Brachiaria brizantha. Twelve Holstein $x$ Zebu crossbred cows were distributed in three $4 \times 4$ Latin Squares. The four treatments consisted of different lipid sources, as follows: no extra source of dietary lipids, diet with cottonseed, diet with soybean oil, and diet with soybean frying oil. The diets were formulated to meet the requirements for maintenance and production of $15 \mathrm{~kg} /$ day, with $3.5 \%$ fat. To study the effect of economic analysis, two economic indicators were used: net present value and internal return rate. A one year simulation was produced to study economic characteristics, computing the depreciation of facilities and machinery in this period. The total cost per animal and per liter of milk produced increased with the use of lipid sources in the diet. All treatments had positive values for profit per animal, with observed values of $R \$ 2.82, R \$ 2.68, R \$ 2.39$ and $R \$ 2.09$, for treatments without lipid source; soybean frying oil as lipid source; cottonseed as lipid source and soybean oil as lipid source, respectively. The internal return rate was more advantageous when no fat source was used in the diet, demonstrating that this treatment is economically better for an investor,
\end{abstract}

Recebido em 2 de maio de 2012

Aceito em 15 de março de 2013

E-mail: rogerio.murta@ifnmg.edu.br 
generating $0.73 \%$ per month. The net present value calculation shows that this investment is viable for all treatments with a 6\% discount rate. Treatment without lipid source had a lower production cost and therefore is more cost-effective. Milk production is not viable for any treatment with return rates of the net present value of 10 and $12 \%$.

Keywords: economic return, fat, performance, production cost

\section{INTRODUÇÃO}

O sistema tradicional de produção pecuária tem se mostrado economicamente pouco eficiente, obrigando os produtores à busca por alternativas que aumentem a lucratividade da propriedade. Existem duas formas básicas de interferir no ganho financeiro real de uma atividade: aumentando seu preço de venda, mas com algumas consequências em relação à demanda, ou implementando uma política de redução de custos e aumento de produtividade, que também favoreceria o aumento da margem, sem, contudo, depender diretamente do fator demanda.

O sistema de exploração em pasto tem provado que alguns de seus conceitos antigos, como baixa lucratividade, sustentabilidade e permanência do produtor na atividade, devem ser revistos e avaliados, podendo-se transformar na opção mais moderna e eficiente para assegurar ganhos econômicos e de produtividade na exploração.

Enquanto a viabilidade técnica da suplementação de animais em pastejo é considerada praticamente consolidada, questionamentos quanto à sua viabilidade econômica existem desde longa data, muito embora comparações econômicas entre os sistemas intensivos e extensivos de pecuária tenham apontado resultados superiores para os sistemas intensivos (Pilau et al., 2003).

A falta de acompanhamento técnico e a escassez de recursos financeiros para investimentos no setor ainda são os principais fatores responsáveis pelos baixos índices produtivos em muitas propriedades leiteiras (Nussio et al., 2003). Isso tem acarretado na opção dos produtores por animais mais rústicos, de menor produção de leite, para suportar os baixos índices tecnológicos dessas propriedades.

Pereira (2000) cita que o retorno financeiro, em relação ao custo de alimentação, constitui o maior determinante dos lucros ou das perdas na exploração leiteira. Esse fator pode variar de acordo com os preços de venda do leite, com o custo de alimentação e com a resposta da vaca ao alimento fornecido. Segundo esse autor, a obtenção de maior retorno econômico depende do custo dos nutrientes nos alimentos disponíveis e do valor de venda do leite.

Rebanhos com maior produtividade apresentam custo de dieta por animal mais elevado, mas a produção, também maior, costuma compensar o investimento. Quando se analisa o custo final da dieta por litro, vacas mais produtivas mostram-se mais rentáveis, visto que o custo por litro é menor (Cepea, 2010).

A avaliação técnica e econômica de sistemas de produção que utilizam indicadores econômicos de rentabilidade pode proporcionar aos pecuaristas informações que indiquem o aumento da produção dos animais e da produtividade por área, com redução dos custos de produção e aumento da rentabilidade (Peres et al., 2009).

Peres et al. (2004) afirmaram que alguns indicadores econômicos podem ser adotados para a avaliação financeira de sistemas de produção, entre eles o valor presente líquido (VPL) e a taxa interna de retorno (TIR).

Objetivou-se, com este estudo, avaliar a viabilidade econômica do uso de diferentes fontes lipídicas no concentrado.

\section{MATERIAL E MÉTODOS}

O experimento de campo foi realizado na Fazenda Paulistinha, no município de Macarani BA, entre os meses de fevereiro e abril de 2009. As análises laboratoriais foram realizadas nas dependências do Laboratório Experimental de Bovinos e nos Laboratórios de Nutrição Animal e Forragicultura e Pastagem do Curso de Zootecnia da Universidade Estadual do Sudoeste da Bahia (Uesb), em Itapetinga - BA.

O trabalho de campo foi implantado em uma área de 42ha, dividida em oito piquetes com média 
de, aproximadamente, 5,3ha cada, formada de Brachiaria brizantha, com água disponível aos animais em todos os piquetes. Foram usados animais niveladores para manter o ajuste na taxa de lotação dos piquetes, que foi de 1,21UA/ha. O período de permanência dos animais nos piquetes variou em função do número de dias para atingir a altura de saída de $20 \mathrm{~cm}$.

Utilizaram-se 12 vacas mestiças Holandês $\mathrm{x}$ Zebu (grau de sangue variando de $1 / 2$ a $3 / 4$ ), com 100 a 150 dias de lactação no início do período experimental e peso corporal médio de
$466,9 \pm 33,2 \mathrm{~kg}$. As 12 vacas lactantes foram distribuídas em três quadrados latinos 4 x 4 . O experimento foi constituído de quatro períodos experimentais, com duração de 17 dias cada, sendo os primeiros 10 dias considerados de adaptação e os sete últimos para coleta de dados.

Os quatro tratamentos foram constituídos de diferentes fontes lipídicas (Tab. 1), como se segue: dieta sem fonte extra de lipídeos; dieta com caroço de algodão; dieta com óleo de soja; e dieta com óleo de soja de fritura. O óleo de soja de fritura foi fornecido por pastelarias da cidade.

Tabela 1. Proporção dos ingredientes das dietas (\% da MS)

\begin{tabular}{|c|c|c|c|c|}
\hline \multirow{2}{*}{ Ingrediente (\%) } & \multicolumn{4}{|c|}{ Fonte extra de lipídeos } \\
\hline & Ausente & Caroço de algodão & Óleo de soja & Óleo de soja de fritura \\
\hline Pastagem & 73,00 & 75,00 & 75,00 & 75,00 \\
\hline Milho grão moído & 19,17 & 12,46 & 15,70 & 15,70 \\
\hline Farelo de soja & 6,40 & 3,08 & 6,38 & 6,38 \\
\hline Caroço de algodão & 0,00 & 8,10 & 0,00 & 0,00 \\
\hline Óleo de soja & 0,00 & 0,00 & 1,53 & 0,00 \\
\hline Óleo de soja de fritura & 0,00 & 0,00 & 0,00 & 1,53 \\
\hline Ureia & 0,46 & 0,43 & 0,43 & 0,43 \\
\hline Calcário calcítico & 0,16 & 0,23 & 0,20 & 0,20 \\
\hline Mistura mineral $^{1}$ & 0,84 & 0,70 & 0,75 & 0,75 \\
\hline
\end{tabular}

${ }^{1}$ Composição: cálcio, 18,5\%; fósforo, 9\%; magnésio, 0,4\%; enxofre, 1\%; sódio, 11,7\%; selênio, 30ppm; cobre, 1500ppm; zinco, 4000ppm; manganês, 1200ppm; iodo, 150ppm; cobalto, 150ppm.

As dietas foram calculadas para suprir as exigências de mantença e produção de $15 \mathrm{~kg}$ de leite/dia, com 3,5\% de gordura, de acordo com o NRC (National..., 2001), com base nos dados da análise bromatológica dos ingredientes da dieta, previamente feita no início do período de adaptação. As dietas foram isonitrogenadas (Tab. 2), mantendo-se a relação volumoso:concentrado de, aproximadamente, 70:30.

Os concentrados foram fornecidos aos animais em baias individuais, providas de cocho $\mathrm{e}$ bebedouro, com uma área de $4 \mathrm{~m}^{2}$. O alimento concentrado foi oferecido duas vezes ao dia, logo após a ordenha. Os animais foram pesados no início do experimento e ao final de cada período, para verificação da variação do peso vivo a cada tratamento.

As vacas foram ordenhadas manualmente, durante todo o experimento, pelo mesmo ordenhador, duas vezes ao dia, às $5 \mathrm{~h} 30$ e às $15 \mathrm{~h}$, e o leite pesado durante todo o período de coleta, do $11^{\circ}$ ao $17^{\circ}$ dia de cada período experimental.

Tabela 2. Composição química das dietas experimentais (\% da MS)

\begin{tabular}{lcccc} 
& \multicolumn{4}{c}{ Fonte extra de lipídeos } \\
\cline { 2 - 5 } Item & Ausente & Caroço de algodão & Óleo de soja & Óleo de soja de fritura \\
\hline Matéria seca & 41,7 & 41,1 & 40,5 & 40,4 \\
Proteína Bruta & 12,0 & 11,9 & 12,0 & 11,9 \\
Extrato etéreo & 4,0 & 5,6 & 5,6 & 5,1 \\
Fibra em detergente neutro & 53,5 & 55,3 & 55,5 & 55,5 \\
Fibra em detergente ácido & 33,0 & 35,7 & 34,5 & 34,5 \\
Carboidratos não fibrosos & 20,2 & 17,5 & 17,7 & 18,2 \\
Nutrientes digestíveis totais & 57,1 & 56,5 & 57,1 & 57,3 \\
\hline
\end{tabular}


A produção de leite corrigida (PLC) para 3,5\% de gordura foi calculada pela seguinte fórmula: PLC $=(0,432+0,1625 \times \%$ gordura do leite $) \times$ produção de leite em kg/dia.

Para estimar a produção fecal, utilizou-se o óxido crômico como indicador externo, fornecido diariamente logo após a ordenha de cada animal, em dose única de $10 \mathrm{~g}$, durante 10 dias, com cinco dias para adaptação e regulação do fluxo de excreção do marcador e cinco dias para coleta das fezes, dentro de cada período experimental, que teve duração de 17 dias. As amostras de fezes foram coletadas diretamente da ampola retal e armazenadas em freezer a $-10^{\circ} \mathrm{C}$.

As amostras de fezes foram acondicionadas em recipientes de alumínio e pré-secas em estufa de ventilação forçada a $60^{\circ} \mathrm{C}$, durante o período de 72 a 96 horas, posteriormente moídas em moinho com peneira dotada de crivos de $1 \mathrm{~mm}$, agrupadas de forma proporcional, com base no peso seco ao ar, constituindo-se amostras compostas de cada animal por período, e armazenadas para posteriores análises. As amostras de fezes foram analisadas por espectrofotometria de absorção atômica (EAA) para dosagem de cromo. Determinou-se a produção fecal, conforme a equação abaixo:

$$
\mathrm{PF}=\mathrm{OF} / \mathrm{COF}
$$

em que $\mathrm{PF}$ é a produção fecal diária (g/dia); OF o óxido crômico fornecido (g/dia) e COF a concentração de óxido crômico nas fezes (g/gMS)

Como indicador interno, foi utilizada a fibra em detergente neutro indigestível (FDNi), de acordo com Detmann et al. (2001); Detmann et al. (2007).

O consumo de MS foi obtido por meio da seguinte equação: $\mathrm{CMS}=\{[(\mathrm{PF} * \mathrm{CIFZ})-$ IS]/CIFR \} + CMSS, em que CMS é o consumo de matéria seca (kg/dia); PF a produção fecal (kg/dia); CIFZ a concentração do indicador presente nas fezes $(\mathrm{kg} / \mathrm{kg})$; IS o indicador presente no suplemento (kg/dia); CIFR a concentração do indicador presente na forragem $(\mathrm{kg} / \mathrm{kg})$ e CMSS o consumo de matéria seca do suplemento ( $\mathrm{kg} / \mathrm{dia})$.

As informações necessárias para a composição dos custos, bem como os dados utilizados (preços, vida útil etc.), foram coletadas junto aos produtores rurais, técnicos de extensão rural e estabelecimentos comerciais da região, considerando-se o preço médio anual. Os custos da terra foram calculados pela compra de 19,23ha, com preços estimados da região. Os custos com o $\mathrm{kg}$ de MS do pasto foram calculados pela produção por hectare, além dos gastos com manutenção e recuperação. Foram consideradas, para avaliação do custo de produção, as metodologias de custos operacionais utilizadas pelo Ipea (Matsunaga et al., 1976, citados por Rodrigues Filho et al., 2002).

A depreciação de benfeitorias, máquinas, equipamentos e animais foi estimada pelo método linear de cotas fixas, com valor final igual a zero, com exceção dos animais. Para a remuneração do capital, utilizou-se a taxa de juro real de $6 \%$ ao ano.

Utilizaram-se, para efeito de estudo da análise econômica, dois indicadores econômicos: o VPL (valor presente líquido) e a TIR (taxa interna de retorno). A expressão para cálculo do VPL é a seguinte:

$\mathrm{VPL}=\sum_{\mathrm{t}=0}^{\mathrm{N}=1} \mathrm{VF} /(1+\mathrm{r})^{\mathrm{t}}$,

em que: $\mathrm{VPL}=$ valor presente líquido; $\mathrm{VF}=$ valor do fluxo líquido (diferença entre entradas e saídas); $\mathrm{n}=$ número de fluxos; $\mathrm{r}=$ taxa de desconto; $\mathrm{t}=$ período de análise $(\mathrm{i}=1,2,3 \ldots)$.

No cálculo do VPL, aplicaram-se três taxas de desconto sobre o fluxo líquido mensal de cada sistema de produção. As taxas adotadas foram 6 , 10 e $12 \%$ ao ano.

Para a TIR, segundo os critérios de aceitação, quanto maior for o resultado obtido no projeto, maior será a atratividade para sua implantação. Assim, a TIR é o valor de $\mathrm{r}$ que iguala a zero a expressão:

$\mathrm{VPL}=\mathrm{VF}_{0}+\frac{\mathrm{VF}_{1}}{(1+\mathrm{r})^{1}}+\frac{\mathrm{VF}_{2}}{(+\mathrm{r})^{2}}+\frac{\mathrm{VF}_{3}}{(1+\mathrm{r})^{3}}+\frac{\mathrm{VF}_{\mathrm{n}}}{(1+\mathrm{r})^{\mathrm{n}}}$,

em que: $\mathrm{VF}=$ fluxos de caixa líquido $(0,1,2$, $3, \ldots, \mathrm{n}) ; \mathrm{r}=$ taxa de desconto.

Para cálculo da TIR e do VPL, fez-se simulação de um ano para estudo de características econômicas, sendo computada, assim, a depreciação de benfeitorias e máquinas nesse período. 
Na Tab. 3, são apresentados os valores médios de venda de leite e esterco, praticados no ano de condução do experimento.

Tabela 3. Preço médio de venda dos produtos no ano de condução do experimento

\begin{tabular}{lcc}
\hline Produto & Unidade & $\begin{array}{c}\text { Valor } \\
\text { unitário } \\
(\mathrm{R} \$)\end{array}$ \\
\hline Leite & Litros (L) & 0,75 \\
Esterco & Toneladas (t) & 40,00 \\
\hline
\end{tabular}

Nas Tab. 4 e 5, são apresentados, respectivamente, de forma detalhada, os dados sobre preços de insumos e serviços, a vida útil e o valor de benfeitoria, máquinas, equipamentos, animal de serviço e terra, utilizados no experimento.

Na Tab. 6, são apresentados os valores médios de consumo de matéria total, consumo de matéria seca do pasto $(\mathrm{kg} / \mathrm{dia})$, consumo de matéria seca do concentrado (kg/dia) e produção de leite diária (kg/dia) dos animais durante o período experimental.

Tabela 4. Preços de insumos e serviços utilizados no experimento

\begin{tabular}{|c|c|c|}
\hline Discriminação & Unidade & $\begin{array}{c}\text { Preço } \\
\text { unitário } \\
(\mathrm{R} \$)\end{array}$ \\
\hline Concentrado $^{1}$ & $\mathrm{~kg}$ de $\mathrm{MS}$ & 0,69 \\
\hline Concentrado $^{2}$ & $\mathrm{~kg}$ de $\mathrm{MS}$ & 0,70 \\
\hline Concentrado $^{3}$ & $\mathrm{~kg}$ de $\mathrm{MS}$ & 0,85 \\
\hline Concentrado ${ }^{4}$ & $\mathrm{~kg}$ de $\mathrm{MS}$ & 0,71 \\
\hline Pasto & $\mathrm{kg}$ de $\mathrm{MS}$ & 0,03 \\
\hline Vermífugo & $\mathrm{mL}$ & 0,06 \\
\hline Carrapaticida & $\mathrm{mL}$ & 0,09 \\
\hline Vacina de aftosa & Dose & 1,50 \\
\hline Mão de obra & $\mathrm{D} / \mathrm{H}$ & 18,00 \\
\hline Outros & & \\
\hline medicamentos & $\mathrm{mL}$ & 0,15 \\
\hline
\end{tabular}

Tabela 5. Vida útil e valor de benfeitorias, máquinas, equipamentos, animais e terra, quantidade utilizada no experimento e seu valor total

\begin{tabular}{lcccc} 
Discriminação & Vida útil (Anos) & $\begin{array}{c}\text { Valor unit. } \\
(\mathrm{R} \$)\end{array}$ & $\begin{array}{c}\text { Quantidade } \\
\text { Valor total } \\
(\mathrm{R} \$)\end{array}$ \\
\hline Balança de curral $(1500 \mathrm{~kg})$ & 15 & $2.638,13$ & 1 & $2.638,13$ \\
Balança eletrônica (30 kg) & 10 & 250,00 & 1 & 250,00 \\
Misturador de ração & 10 & $3.500,00$ & 1 & $3.500,00$ \\
Carrinho de mão & 2 & 75,00 & 1 & 75,00 \\
Unidades de pequeno valor & 2 & 35,30 & 1 & 35,30 \\
Pá de bico & 2 & 22,00 & 1 & 22,00 \\
Garfo de quatro dentes & 2 & 12,00 & 1 & 12,00 \\
Curral & 20 & $8.000,00$ & 1 & $8.000,00$ \\
Vacas & 8 & $2.000,00$ & 12 & $24.000,00$ \\
Terra nua & - & $4.000,00$ & 19,23 & $76.920,00$ \\
Valor fixo investido & & & $115.452,43$ \\
\hline
\end{tabular}

Tabela 6. Consumo de matéria seca e produção de leite de vacas alimentadas com diferentes fontes lipídicas

\begin{tabular}{lcccccc}
\hline \multirow{2}{*}{ Variável } & \multicolumn{5}{c}{ Fonte extra de lipídeos } \\
\cline { 2 - 6 } & Ausente & Caroço de algodão & Óleo de soja & $\begin{array}{c}\text { Óleo de soja } \\
\text { de fritura }\end{array}$ & Média & $\begin{array}{c}\text { CV } \\
(\%)^{*}\end{array}$ \\
\hline CMS $^{1}(\mathrm{~kg} /$ dia) & 14,78 & 16,11 & 16,14 & 15,98 & 15,7 & 12,7 \\
$\begin{array}{l}\text { CMSpasto } \\
\text { (kg/dia) }\end{array}$ & 10,78 & 12,05 & 12,19 & 12,01 & 11,8 & 15,7 \\
$\begin{array}{l}\text { CMSconcentrado } \\
\text { (kg/dia) }\end{array}$ & 4,00 & 4,06 & 3,95 & 3,97 & 4,0 & - \\
$\begin{array}{l}\text { Produção de leite } \\
\text { (kg/dia) }\end{array}$ & 12,25 & 11,80 & 12,32 & 12,31 & 12,2 & 5,5 \\
\hline $\begin{array}{l}* \text { Coeficiente de variação; }{ }^{1} \text { CMS = consumo matéria seca; }{ }^{2} \text { CMSpasto } \\
{ }^{3} \text { CMSconcentrado = consumo matéria seca do pasto; }\end{array}$
\end{tabular}


Os resultados de consumo, conversão alimentar, variação do peso corporal e produção de leite foram submetidos à análise de variância e ao teste de médias, aplicando-se o teste de Duncan a $5 \%$ de probabilidade para comparação das médias.

\section{RESULTADOS E DISCUSSÃO}

Os valores de renda bruta por animal variaram de $\mathrm{R} \$ 9,58$ a $\mathrm{R} \$ 9,22$ (Tab. 7), com maior valor para o tratamento com óleo de soja como fonte lipídica e menor valor para o tratamento com caroço de algodão como fonte lipídica. Mendes (2010) utilizou $23,3 \%$ de concentrado na dieta de vacas leiteiras em pastagens e relatou renda bruta de R\$ 8,59 por animal, valor inferior ao encontrado neste trabalho. A comercialização do esterco incorporou valores à renda bruta da ordem de 3,$9 ; 4,0 ; 3,6$ e 3,4\% para os tratamentos ausente de fonte extra de lipídeos; caroço de algodão como fonte lipídica; óleo de soja como fonte lipídica e óleo de soja de fritura como fonte lipídica, respectivamente.

O valor do custo operacional efetivo, que mostra quanto de recurso está sendo utilizado para cobertura de despesas, foi elevado com a utilização das fontes lipídicas, devido ao maior custo dos concentrados que utilizaram fontes lipídicas e ao maior consumo de pasto dos animais desses tratamentos, demonstrando, assim, a importância da participação do custo de alimentação no total geral de custos.

Os custos operacionais efetivos (COE) representaram gastos da ordem de 71,5; 71,9; 74,4 e $72,1 \%$ do custo total de produção para os tratamentos ausente de fonte extra de lipídeos; caroço de algodão como fonte lipídica; óleo de soja como fonte lipídica e óleo de soja de fritura como fonte lipídica, respectivamente, sendo observado maior valor para o tratamento com óleo de soja como fonte lipídica, o que pode ser atribuído ao maior gasto com alimentação (Tab.7).

De acordo com Simith (2003), o custo operacional efetivo não deve ultrapassar $65 \%$ da renda bruta. No presente trabalho, os índices dos tratamentos ausente de fonte extra de lipídeos; caroço de algodão como fonte lipídica; óleo de soja como fonte lipídica e óleo de soja de fritura como fonte lipídica foram 50,$4 ; 53,2 ; 58,1$ e $51,9 \%$, respectivamente, mostrando-se inferiores ao descrito por Simith.

Em sistemas de produção intensiva, a alimentação pode representar até $70 \%$ dos custos operacionais efetivos. Mas, em propriedades com sistema semi-intensivo e com menos recursos técnicos, esses insumos respondem por, aproximadamente, $50 \%$ dos custos. Desse modo, fica evidente que maior investimento na produção propicia melhores resultados, devido à diluição dos custos fixos (Cepea, 2010).

Os resultados encontrados no presente trabalho foram de 68,7;69,2; 72,9 69,6\% de gasto com alimentação em relação aos custos operacionais efetivos, para os tratamentos ausente de fonte extra de lipídeos; caroço de algodão como fonte lipídica; óleo de soja como fonte lipídica e óleo de soja de fritura como fonte lipídica, respectivamente. O elevado custo dos ingredientes do concentrado, durante o ano de 2009, foi o responsável pelos altos valores no presente estudo.

De acordo com Martins et al. (2000), na criação de ruminantes, a alimentação é responsável por grande parte dos custos (60 a 70\%). Portanto, é importante conhecer as características dos alimentos e seu balanceamento na formulação de rações, as quais devem ser formuladas para suprir as necessidades dos animais, explorando sua máxima capacidade digestiva, de modo a atingir seu potencial genético para o aproveitamento da ração.

Os gastos indiretos com depreciação e juros foram os mesmos para todos os tratamentos $(\mathrm{R} \$$ $1,92)$, pois todos os animais estavam no mesmo local e recebendo os mesmos tratamentos.

Os valores de custo operacional total, que engloba a depreciação, apresentaram o mesmo comportamento do custo operacional efetivo, pois a infraestrutura e os animais utilizados foram os mesmos em todos os tratamentos. $\mathrm{O}$ custo total por animal e por litro de leite produzido, que engloba a remuneração de capital (custo de oportunidade), cresceu com a utilização das fontes lipídicas na dieta. 
Tabela 7. Renda bruta, custo operacional efetivo, custo operacional total, custo total, lucro por vaca/dia e produção de leite por kg de concentrado

\begin{tabular}{|c|c|c|c|c|c|c|c|c|c|c|}
\hline \multirow{4}{*}{ Variável } & \multirow{4}{*}{ Unid } & \multirow{4}{*}{$\begin{array}{c}\text { Vr. } \\
\text { Unit. } \\
(\mathrm{R} \$)\end{array}$} & \multicolumn{8}{|c|}{ Fonte extra de lipídeos } \\
\hline & & & \multicolumn{2}{|c|}{ Ausente } & \multicolumn{2}{|c|}{$\begin{array}{l}\text { Caroço de } \\
\text { algodão }\end{array}$} & \multicolumn{2}{|c|}{ Óleo de soja } & \multicolumn{2}{|c|}{$\begin{array}{c}\text { Óleo de soja } \\
\text { de fritura }\end{array}$} \\
\hline & & & Qtde & $\mathrm{Vr}$ & Qtde & $\mathrm{Vr}$ & Qtde & $\mathrm{Vr}$ & Qtde & $\mathrm{Vr}$ \\
\hline & & & \multicolumn{8}{|c|}{ Renda bruta } \\
\hline Venda de leite & $\mathrm{kg}$ & 0,75 & 12,25 & 9,19 & 11,80 & 8,85 & 12,32 & 9,24 & 12,31 & 9,23 \\
\hline Venda esterco & $\mathrm{kg}$ & 0,035 & 10,48 & 0,37 & 10,47 & 0,37 & 9,71 & 0,34 & 9,44 & 0,33 \\
\hline Total & & & & 9,56 & & 9,22 & & $\mathbf{9 , 5 8}$ & & 9,56 \\
\hline & & & \multicolumn{8}{|c|}{ Custo operacional efetivo } \\
\hline Mão de obra & $\mathrm{d} / \mathrm{H}$ & 18,00 & 0,042 & 0,75 & 0,042 & 0,75 & 0,042 & 0,75 & 0,042 & 0,75 \\
\hline Concentrado & $\mathrm{kg}$ & $*$ & 4,34 & 2,99 & 4,34 & 3,04 & 4,34 & 3,69 & 4,34 & 3,08 \\
\hline Pasto & $\mathrm{kg}$ & 0,03 & 10,78 & 0,32 & 12,05 & 0,36 & 12,19 & 0,37 & 12,21 & 0,37 \\
\hline Energia & $\mathrm{KW} / \mathrm{h}$ & 0,27 & 0,40 & 0,11 & 0,40 & 0,11 & 0,40 & 0,11 & 0,40 & 0,11 \\
\hline Reparo benfeitorias & $\mathrm{R} \$$ & & & 0,60 & & 0,60 & & 0,60 & & 0,60 \\
\hline Reparo máquinas & $\mathrm{R} \$$ & & & 0,05 & & 0,05 & & 0,05 & & 0,05 \\
\hline Subtotal & & & & 4,82 & & 4,91 & & 5,57 & & 4,96 \\
\hline & & & \multicolumn{8}{|c|}{ Custo operacional total } \\
\hline $\mathrm{COE}$ & & & & 4,82 & & 4,91 & & 5,57 & & 4,96 \\
\hline Dep. benfeitorias & $\mathrm{R} \$$ & & & 0,09 & & 0,09 & & 0,09 & & 0,09 \\
\hline Dep. máquinas & $\mathrm{R} \$$ & & & 0,11 & & 0,11 & & 0,11 & & 0,11 \\
\hline Depreciação vacas & $\mathrm{R} \$$ & & & 0,55 & & 0,55 & & 0,55 & & 0,55 \\
\hline Subtotal & $\mathrm{R} \$$ & & \multicolumn{8}{|c|}{ Custo total } \\
\hline COT & & & & 5,57 & & 5,66 & & 6,32 & & 5,71 \\
\hline Juros benfeitorias & $\mathrm{R} \$$ & & & 1,16 & & 1,16 & & 1,16 & & 1,16 \\
\hline Juros máquinas & $\mathrm{R} \$$ & & & 0,01 & & 0,01 & & 0,01 & & 0,01 \\
\hline Custo total/animal & $\mathrm{R} \$$ & & & 6,74 & & 6,83 & & 7,49 & & 6,88 \\
\hline Custo/litro leite & $\mathrm{R} \$$ & & & 0,55 & & 0,58 & & 0,61 & & 0,56 \\
\hline $\begin{array}{l}\text { Margem } \\
\text { bruta/animal }^{1}\end{array}$ & $\mathrm{R} \$$ & & & 4,74 & & 4,31 & & 4,01 & & 4,60 \\
\hline $\begin{array}{l}\text { Margem } \\
\text { líquida/animal }^{2}\end{array}$ & $\mathrm{R} \$$ & & & 3,99 & & 3,56 & & 3,26 & & 3,85 \\
\hline Lucro/animal $^{3}$ & & & & 2,82 & & 2,39 & & 2,09 & & 2,68 \\
\hline $\mathrm{COE} / \mathrm{CT}^{4}$ & $\%$ & & & 71,5 & & 71,9 & & 74,4 & & 72,1 \\
\hline $\mathrm{COE} / \mathrm{RB}^{5}$ & $\%$ & & & 50,4 & & 53,2 & & 58,1 & & 51,9 \\
\hline $\begin{array}{l}\text { Gto } \\
\text { alimentação/COE }\end{array}$ & $\%$ & & & 68,7 & & 69,2 & & 72,9 & & 69,6 \\
\hline Gto concentrado/CT & $\%$ & & & 44,4 & & 44,5 & & 49,3 & & 44,8 \\
\hline Gto concentrado/RB & $\%$ & & & 31,3 & & 33,0 & & 38,5 & & 32,2 \\
\hline $\mathrm{kg}$ de leite/kg conc & $\mathrm{kg}$ & & & 2,82 & & 2,72 & & 2,84 & & 2,84 \\
\hline
\end{tabular}

*Valor unitário do concentrado $=\mathrm{R} \$ 0,69$ sem fonte extra de lipídeos, $\mathrm{R} \$ 0,70$ caroço de algodão como fonte lipídica, $\mathrm{R} \$ 0,85$ óleo de soja como fonte extra de lipídeos e R $\$ 0,71$ óleo de soja de fritura como fonte extra de lipídeos; ${ }^{1}$ renda bruta - custo operacional efetivo; ${ }^{2}$ renda bruta - custo operacional total; ${ }^{3}$ renda bruta - custo total; ${ }^{4} \mathrm{COE}=$ custo operacional efetivo e $\mathrm{CT}=$ custo total; ${ }^{5} \mathrm{COE}=$ custo operacional efetivo e $\mathrm{RB}=$ receita bruta.

A margem bruta/animal está apresentada na Tab. 7, sendo observados valores de $\mathrm{R} \$ 4,74 ; \mathrm{R} \$$ 4,$31 ; \mathrm{R} \$ 4,01$ e $\mathrm{R} \$ 4,60$ para os tratamentos ausente de fonte extra de lipídeos; caroço de algodão como fonte lipídica; óleo de soja como fonte lipídica e óleo de soja de fritura como fonte lipídica, respectivamente, com valores positivos para todos os tratamentos, o que demonstra que o custo fixo por animal deve ser diluído ao máximo para obter maior retorno econômico na pecuária.

Observou-se, por meio da análise econômica, que todos os tratamentos apresentaram valores 
positivos de lucro por animal, sendo observados valores de $\mathrm{R} \$ 2,82 ; \mathrm{R} \$ 2,68 ; \mathrm{R} \$ 2,39$ e $\mathrm{R} \$ 2,09$ para os tratamentos ausente de fonte extra de lipídeos; óleo de soja de fritura como fonte lipídica; caroço de algodão como fonte lipídica e óleo de soja como fonte lipídica, respectivamente, tendo o tratamento ausente de fonte extra de lipídeos apresentado o maior lucro/animal. Tal fato pode ser explicado pelo menor custo/animal apresentado neste tratamento (Tab. 7), sendo este menor custo atribuído ao menor CMST (Tab. 6) e ao custo do kg de MS do concentrado (Tab. 4).

Apesar de os parâmetros de produção serem favoráveis a todas as dietas, o lucro por animal foi menor nas dietas que continham fontes lipídicas (Tab. 7), sendo o maior valor encontrado na dieta ausente de fonte lipídica ( $\mathrm{R} \$$ 2,82), o que demonstra menor eficiência econômica das dietas que continham óleo, as quais, mesmo apresentando renda bruta igual ou maior que a dieta ausente de fonte extra de lipídeos, não foram capazes de apresentar o mesmo, ou o melhor, custo-benefício.

É importante ressaltar que outros aspectos podem interferir na viabilidade econômica da inclusão de fontes lipídicas na dieta, assim como a época de parição das vacas, a cota de leite e, principalmente, a qualidade da forragem utilizada, que deve ser observada com bastante cautela por técnicos e produtores.

As fontes lipídicas não alteraram $(\mathrm{P}>0,05)$ a relação $\mathrm{kg}$ de leite $/ \mathrm{kg}$ de concentrado com a utilização das fontes lipídicas. De acordo com Costa et al. (2011), com esse parâmetro, pode-se chegar a uma equação para saber qual nível de concentrado será mais interessante em um determinado momento, sendo esta igual a: $\mathrm{PMC}=$ plc $\times$ PL, em que $\mathrm{PMC}=$ preço máximo do concentrado, plc $=$ produção de leite por quilo de concentrado e $\mathrm{PL}=$ preço do leite.

Com esta equação, o produtor poderá se abster das oscilações de mercado, tanto para o preço do leite quanto para o preço do concentrado, que são os parâmetros mais representativos para o cálculo de viabilidade econômica. Outro parâmetro de muita importância, a resposta do animal, é também contemplado por esta equação (Costa et al., 2011).

A TIR foi mais vantajosa quando não se utilizou fonte lipídica na dieta, o que demonstra que este tratamento é economicamente mais interessante para um investidor, gerando $0,73 \%$ ao mês, enquanto nas dietas com presença de fontes lipídicas, os valores foram de 0,$61 ; 0,52$ e $0,69 \%$ ao mês, para os tratamentos com caroço de algodão, óleo de soja e óleo de soja de fritura, respectivamente (Tab. 8). Costa et al. (2011), ao trabalharem com diferentes níveis de concentrado na alimentação de vacas leiteiras confinadas, encontraram TIR de 1,72\% ao mês, com a utilização de $24 \%$ de concentrado na dieta, resultado que se encontra acima dos verificados no presente trabalho. Tal valor pode ser explicado pelo menor capital fixo investido para produção e maior produtividade dos animais. Já Mendes (2010) utilizou 23,3\% de concentrado na dieta de vacas leiteiras em pastagens e relatou TIR de 0,68\% ao mês, valor próximo aos encontrados no presente trabalho.

Tabela 8. Taxa interna de retorno (TIR) mensal e valor presente líquido (VPL) para taxas de desconto de 6,10 e $12 \%$, respectivamente, para um ano

\begin{tabular}{lcccc}
\hline & \multicolumn{4}{c}{ Fonte extra de lipídeos } \\
\cline { 2 - 5 } Variável & Ausente & $\begin{array}{c}\text { Caroço de } \\
\text { algodão }\end{array}$ & $\begin{array}{c}\text { Óleo de } \\
\text { soja }\end{array}$ & $\begin{array}{c}\text { Óleo de soja de } \\
\text { fritura }\end{array}$ \\
\hline TIR (\%) & 0,73 & 0,61 & 0,52 & 0,69 \\
VPL 6\% & $3.247,47$ & $1.502,20$ & 287,71 & $2.743,52$ \\
VPL 10\% & $-1.431,23$ & $-3.134,55$ & $-4.319,86$ & $-1.923,07$ \\
VPL 12\% & $-3.748,88$ & $-5.431,12$ & $-6.601,76$ & $-4.234,63$ \\
\hline
\end{tabular}

O cálculo do VPL demonstra que este investimento é viável para todos os tratamentos, com taxa de $6 \%$ de desconto. E, quando se utilizam taxas de 10 e $12 \%$, todos os tratamentos são economicamente inviáveis. Mendes (2010) também observou viabilidade apenas com taxa de desconto de $6 \%$ e nível máximo de concentrado de $23,3 \%$ na dieta de vacas leiteiras em pastagens. Ainda de acordo com Mendes (2010), para a taxa de desconto de $10 \%$, só o 
tratamento sem suplementação concentrada foi viável.

\section{CONCLUSÃO}

A inclusão de fontes lipídicas na dieta, nas condições deste trabalho, provocou redução na rentabilidade da produção de leite.

\section{AGRADECIMENTOS}

À Universidade Estadual do Sudoeste da Bahia UESB. À Fundação de Amparo à Pesquisa do estado de Minas Gerais - FAPEMIG pelo auxílio financeiro.

\section{REFERÊNCIAS}

CEPEA-Esalq/USP, Alimentação: Boletim do leite - Custo da dieta à base de milho e concentrado reduz em novembro. Boletim Técnico. Disponível em: <http://www.cepea. esalq.usp.br/leite/boletim/183/completo.pdf.> Acessado em: 13 Jan. 2010.

COSTA, L.T.; SILVA, F.F.; VELOSO, C.M. et al. Análise econômica da adição de níveis crescentes de concentrado em dietas para vacas leiteiras mestiças alimentadas com cana-deaçúcar. Rev. Bras. Zootec., v.40, p.1155-1162, 2011.

DETMANN, E.; PAULINO, M.F.; ZERVOUDAKIS, J.T. et al. Cromo e indicadores internos na determinação do consumo de novilhos mestiços, suplementados, a pasto. Rev. Bras. Zootec., v.30, p.1600-1609, 2001.

DETMANN, E.; VALADARES FILHO, S.C.; HENRIQUES, L.T. et al. Reparametrização do modelo baseado na lei de superfície para predição da fração digestível da fibra em detergente neutro em condições brasileiras. Rev. Bras. Zootec., v.36, p.155-164, 2007.

MARTINS, A.S.; PRADO, I.N.; ZEOULA, L.M. et al. Digestibilidade aparente de dietas contendo milho ou casca de mandioca como fonte energética e farelo de algodão ou levedura como fonte proteica em novilhas. Rev. Bras. Zootec., v.29, p.269-277, 2000.
MENDES, F.B.L. Vacas mestiças em pastejo de brachiaria brizantha recebendo diferentes niveis de concentrado na dieta. 2010. 71f. Dissertação (Mestrado em Zootecnia) - Universidade Estadual do Sudoeste da Bahia - UESB, Itapetinga-BA, 2010.

NATIONAL Research Council - NRC. Nutrient requirements of dairy cattle. 7.ed. Washington, D.C.: National Academy of Sciences, 2001. $381 \mathrm{p}$.

NUSSIO, L.G.; SCHMIDT, P.; PEDROSO, A.F. Silagem de cana-de-açúcar. In: FORRAGICULTURA E PASTAGENS: TEMAS EM EVIDÊNCIA SUSTENTABILIDADE, 1., 2003, Lavras. Anais... Lavras: UFLA, 2003. p.49-74. (Resumo).

PEREIRA, J.C. Vacas leiteiras: aspectos práticos da alimentação. Viçosa, MG: Aprenda Fácil, 2000. 198p.

PERES, A.A.C.; SOUZA, P.M.; VÁSQUEZ, H.M. et al. Análise econômica de sistemas de produção a pasto para bovinos no município de Campos dos Goytacazes, RJ. Rev. Bras. Zootec., v.33, p.1557-1563, 2004.

PERES, A.A.C.; VÁSQUEZ, H.M.; SOUZA, P.M. et al. Análise financeira e de sensibilidade de sistemas de produção de leite em pastagem. Rev. Bras. Zootec., v.38, p.2072-2078, 2009.

PILAU, A.; ROCHA, M.G.; SANTOS, D.T. Análise Econômica de Sistemas de Produção para Recria de Bezerras de Corte. Rev. Bras. Zootec., v.32, p.966-976, 2003.

RODRIGUES FILHO, M.; MANCIO, A.B.; GOMES, S.T. et al. Avaliação econômica do confinamento de novilhos de origem leiteira, alimentados com diferentes níveis de concentrado e de cama de frango. Rev. Bras. Zootec., v.31, p.2055-2069, 2002.

SIMITH, T.R. Melhorando a lucratividade de fazendas leiteiras através do aumento na eficiência das operações. In: CONGRESSO INTERNACIONAL REHAGRO, v.1., 2003, Sete Lagoas. Anais... Sete Lagoas:[s.n] 2003. p.41. (Resumo). 